\title{
Las condiciones laborales de los/as bailarines/as durante la primera mitad del siglo XX
}

Fecha de recepción: 19/03/2018. Fecha de aceptación: 11/05/2018.

\begin{abstract}
Resumen
El artículo describe y analiza críticamente las condiciones laborales de las/os bailarines del circuito oficial y no-oficial de la danza, en Capital Federal (Buenos Aires, Argentina), durante la primera mitad del siglo XX, haciendo particular hincapié en la época del primer peronismo (1946-1955). El artículo propone que en las décadas de 1940 y 1950 la práctica de la danza se profesionalizó, y detalla uno de los aspectos de esto: el laboral. Se sostiene que gracias al contexto político y social basado en la defensa de los derechos de los/as trabajadores/as, los/as bailarines del ámbito oficial (Teatro Colón) consiguieron avanzar en sus derechos laborales. Por otra parte, se plantea que debido al origen de la danza moderna local (la compañía privada "Ballet Winslow"), también en la misma época, se instaura otro tipo de producción en la práctica de la danza argentina, signado por la precarización laboral de los/as bailarines, que persiste hasta la actualidad en el ámbito no-oficial.
\end{abstract}

\section{The Working Conditions of Dancers During the First Half of $20^{\text {th }}$ Century}

\begin{abstract}
The article describes and critically analyzes the labor conditions of dancers of the official and non-official scopes of dance in Buenos Aires, Argentina, during the first half of the 2oth century, focusing on the period of the First Peronism (1946-1955). The article proposes that dance practice was professionalized during the 1940s and 1950 s, and it considers particularly the labor aspect. I argue that, due to the social and political context based on the defense of workers' rights, the dancers of the official scope (Teatro Colón) were able to improve their labor rights. On the other hand, I argue that, due to the origin of the local modern dance (the private company "Ballet Winslow"), also in the 40s and 50s, another type of production is established in the Argentine dance practice: one that is marked by the labor precarization of dancers and that persists until the present time in the unofficial scope.
\end{abstract}

Palabras clave

danza; trabajo; peronismo; condiciones laborales; condiciones de producción
Keywords

Dance; Work; Peronism; Labor Conditions; Production Conditions 


\section{Introducción}

En la Argentina, la danza escénica comenzó alrededor de 1913 con la llegada de la compañía franco-rusa Les Ballets Russes, pero recién entre las décadas de 1940 y 1950 se consolidó como una práctica artística (Cadús, 2017a). Este arte, de la mano de la clase alta y de la intelectualidad porteña, se estructuró bajo una concepción elitista, concibiendo a la danza como un arte teatral erudito, cuyos representantes de la época eran, en primer lugar el ballet - particularmente el denominado ballet moderno que sigue la estética impuesta por Les Ballets Russes y sus compañías derivadas-, y luego la danza moderna - a partir de su vertiente norteamericana-(Tambutti, 2011).

Tanto para el ballet - perteneciente a instituciones oficiales como el Teatro Colóncomo para la danza moderna - que participaba de distintos espacios, pero que, en general, podemos denominar como danza no-oficial-, los años cuarenta y cincuenta constituyeron el momento de definición de la profesionalización de los agentes de la danza (Cadús, 2017a).

El presente artículo expone uno de los aspectos de esta profesionalización, a saber, las condiciones laborales de los/as bailarines tanto oficiales como del ámbito no-oficial. Cabe aclarar que el análisis refiere sólo a lo que sucedía en la Capital Federal de la Argentina, tomando esta ciudad como representativa, ya que era vista como un faro y modelo a reproducir en otras provincias y ciudades del país.

El estudio se concentra en dos espacios de producción: por un lado, el ámbito oficial, referido a aquel dependiente del Estado, representado en este caso por el Ballet Estable del Teatro Colón, perteneciente a la municipalidad de la ciudad de Buenos Aires. Por el otro lado, se reconstruyen las características del ámbito no-oficial, es decir aquel que no depende -en su totalidad- del Estado, representado en la época, por la incipiente danza moderna.

Proponemos, en primer lugar, que es en las décadas de 1940 y 1950 cuando se consolida la práctica artística de la danza, reflejándose en su profesionalización. A partir del primer peronismo, las condiciones de trabajo de los/as bailarines del Ballet Estable del Teatro Colón se vieron mejoradas, debido al hincapié estatal en la sindicalización y el trabajo como estructurante de la sociedad, lo cual se evidencia en los orígenes mismos del peronismo con Perón a cargo de la Secretaría de Trabajo y Previsión desde 1943. A partir de 1947, la estabilidad laboral del Ballet se estructura, así como el ingreso por concurso. También se mejoran los sueldos y las condiciones materiales de trabajo. Sin embargo, al asumir el poder la Revolución Libertadora, en 1955, muchas de estas conquistas se pierden. Se demuestra de este modo que la precariedad laboral de los/ as bailarines oficiales está dada no sólo por las circunstancias internas del Teatro, sino por la inestabilidad estatal de la época.

En segundo lugar, es en los años cuarenta que se produce la primera modernización estética en la práctica de la danza, lo cual introdujo nuevos agentes y modos de producción que se insertaron en un ámbito no-oficial (Cadús, 2017a). El asentamiento en el país, en 1944, de la bailarina norteamericana Miriam Winslow, y su creación de la primera compañía profesional de danza moderna, el Ballet Winslow (1944-1948), promovieron el inicio de otro modo de producción tanto estético como económico (Cadús, 2017a).

La profesionalización de los/as bailarines, dada en esta época, resulta nodal para consolidar la práctica de la danza y cabe destacar que, en cuanto a la danza clásica, la misma llega de la mano de las políticas públicas gubernamentales. Mientras que en el caso de la danza moderna, signada por su origen de compañía privada (el Ballet Winslow), se establece una precarización laboral de los/as trabajadores de la danza. 
Cabe aclarar que nos interesa estudiar estas décadas ya que consideramos que es en este momento en el que se establecen dos modelos opuestos de producción y trabajo en la danza -que denominamos como el "oficial" y el "no-oficial"- que persisten hasta la actualidad.

En este sentido, como el "ángel de la historia" (Benjamin, 2011), buscamos a través de la pesquisa histórica, desentrañar aquellos sustentos primigenios de estos dos modos de trabajo, para pensar críticamente el presente.

Dado que no existen estudios precedentes en la temática, tomamos como fuentes principales para la reconstrucción de este mundo del trabajo, las biografías publicadas de algunos/as bailarines de ballet como Beatriz Moscheni (Manso, 2009); las entrevistas a bailarines y coreógrafos/as de danza moderna, compiladas por Marcelo Isse-Moyano en La danza moderna argentina cuenta su historia (2006), y por Paulina Ossona en Destinos de un destino: La danza moderna argentina por sus protagonistas (2003); así como entrevistas personales realizadas a bailarines de la época como Enrique Lommi (2015), Eliseo Pinto, Beatriz Moscheni y Elena Pérez (2015).

\section{Un clima de época}

La planificación del primer peronismo plasmada en los Planes Quinquenales, vislumbraba el lugar que debería ocupar el intelectual como trabajador, es decir, "como individuo con capacidades de producir bienes simbólicos que fueran funcionales a un proyecto de país, económicamente independiente, con justicia social y soberano en materia política" (Lifschitz, 2008: 4).

Antes de pasar al análisis del caso de la danza, cabe destacar la concepción del intelectual como trabajador propuesta en la planificación cultural expuesta en la publicación Guía quincenal de la actividad artística e intelectual argentina, la cual pretendía que éstos pudieran hacer valer sus derechos frente a ciertas arbitrariedades, como la falta de garantía de honorarios pautados. Esta publicación funcionó como difusora de las nuevas organizaciones intelectuales como la ADEA (Asociación de Escritores Argentinos), quienes impulsaron como iniciativa oficial un anteproyecto de Estatuto del Trabajador Intelectual, cuyo nombre recuerda al Estatuto del Peón Rural implementado por Perón en 1944.

A partir de 1949, la Guía... comenzó la publicación por entregas de este documento redactado por la Junta de Intelectuales, para ser sometido a la consideración del gobierno y aprobado oportunamente por el Congreso Nacional (Guía quincenal de la actividad artistica e intelectual argentina, 1949). La Junta Nacional de Intelectuales fue formada por la Subsecretaría de Cultura en 1948 a fin de que trabajara en este Estatuto, el cual debía resolver los problemas de la cultura argentina en lo que correspondía a la protección al intelectual (Lifschitz, 2008). Estaba compuesta por Eduardo Acevedo Díaz, Luis César Amadori, Cesáreo Bernaldo de Quirós, Delfina Búnge de Gálvez, Juan A. Bussolini, Alejandro Bustillo, Antonio P. Castro, Juan Alfonso Carrizo, Agustín G. Casá, Agustín Durañona y Vedia, Ángel Ferreira Cortés, Carlos Ibarguren, Julio B. Jaimes Répide, Rafael Jijena Sánchez, Emiliano Mac Donagh, Arnaldo M. G. Malfatti, Gustavo Martínez Zuviría, Luis V. Ochoa, Athos Palma, Rosauro Pérez Aubone, y Vicente Roselli (Anteproyecto de Estatuto de Trabajador Intelectual, 1949).

El Estatuto consideraba como trabajador intelectual a "todo el que dedica actualmente, o ha dedicado antes, una parte considerable de su tiempo a la investigación científica o a producir obras de cultura (...)" (Guia quincenal de la actividad artística e intelectual argentina, 1949: 58). En este sentido, los/as bailarines y coreógrafos/as, 
estarían incluidos en esta definición. Estas personas deberían estar inscriptas en el "Registro de los Trabajadores Intelectuales Argentinos" que se crearía, formando la "Confederación de Trabajadores Intelectuales" a nivel nacional dividida en tres ramas: Ciencias, Letras, y Artes (Guía quincenal de la actividad artística e intelectual argentina, 1949: 58).

Pese a este intento de agrupamiento laboral de los escritores, artistas e intelectuales, la propuesta no prosperó (Lifschitz, 2008). Sin embargo, constituye un hecho realmente significativo el intento de regular la actividad intelectual en sus distintas especificidades - tarea que hasta el día de hoy no se ha logrado implementar-.

\section{Bailarines oficiales}

Los/as bailarines de ballet accedían a la profesión a través de su formación en las diferentes escuelas de danza. Estas instituciones públicas ${ }^{1}$ y privadas formaron a la segunda camada de bailarines argentinos que integraron parte del Ballet Estable del Colón. Estos niños y niñas se incorporaban a la vida laboral de la danza aun siendo estudiantes. Participaban de las óperas y ballets en los roles de niños, por ejemplo en La Bella Durmiente del Bosque eran hongos, frutillas o gatos. "Todo era 'ad-honorem', [relata Beatriz Moscheni en su biografía] pero nosotras estábamos muy felices de salir a escena, bailar gratis y a cualquier hora" (cit. in Manso, 2009: 22).

Una vez terminada la escuela tenían la posibilidad de concursar e ingresar al Ballet Estable y hacer una carrera dentro de éste. Concursaban cada uno o dos años para mantener el puesto que ya tenían o para ascender a uno nuevo: Corifeo, Cuerpo de Baile, Solistas, Primer/a bailarín/a. De este modo, tenían un trabajo asegurado y bien remunerado. El sueldo de una Bailarina de $1^{\text {a }}$ fila del Cuerpo de Baile, en 1947, era de \$300 (Manso, 2009: 37). Resultan esclarecedoras al respecto, las palabras de Moscheni al relatar su primer cobro, a los 17 años:

Llegando el día 28 de julio me avisaron de que debía formar fila para recibir mi primer sueldo. Cuando vi esa inmensa cantidad de pesos, la cajera me aconsejó: “Ay, nenita, te veo con cara de susto y te voy a ayudar con este dinero. Vamos a envolverlo con un papel de diario que tengo a mano, y vos colocátelo dentro del corpiño, y tené cuidado cuando viajes" - Cuando llegué a casa, y saqué el paquetito para mostrárselo a mi padre, lo puse sobre la mesa, y papá mirando esos pesos me dijo: - "Valió la pena pasar tantos años de inconvenientes y esfuerzos, hasta llegar por fin a este día, con un puesto fijo y un primer sueldo. Tu madre estaría tan orgullosa de lo que haz [sic] alcanzado, como yo lo estoy ahora." Y pensando siempre en lo mejor, me consultó si me parecía bien que se repartiera en 3 partes, $1^{\circ}$ comprarme ropa y peinarme a la moda. $2^{\circ}$ enviarle a mi hermano que seguía en Córdoba, dinero para cigarrillos, golosinas, corbatas, para sus gustos. $3^{\circ}$ depositar otra parte todos los meses en la libreta de la Caja de Ahorro Postal-que ya tenía desde la escuela primaria- porque esos ahorros serían para mi vejez (cit. in Manso, 2009: 37).

Pero esto no siempre fue así, en años anteriores, tal como recuerda el primer bailarín Enrique Lommi, a su ingreso en 1941, le pagaban 90 pesos por mes, pero aclara que en la época había restaurantes cercanos al Colón en los que se comía un menú completo por 70 centavos (Lommi, 2015). También Eliseo Pinto recuerda su ingreso, cuando en un principio, participaba como "refuerzo", siendo aún estudiante, y le pagaban \$1 por ensayo y \$5 por función (Moscheni, Pérez y Pinto, 2015). Luego fue Supernumerario y cobraba \$70 por mes. A su vez, relata Esmeralda Agoglia que cuando ella ingresó en 1942, fue para reemplazar al Ballet Estable, en las puestas operísticas, ya
1. La escuela de danza del Teatro Colón se creó en 1919 y en 1937 pasó a formar parte de la Escuela de Ópera del Teatro Colón actualmente Instituto Superior de Arte del Teatro Colón-; el Conservatorio Nacional de Música, Arte Escénico y Declamación se fundó en 1924 y en 1950, se desprende de éste, la Escuela Nacional de Danzas (Cadús, 2017a). 
que se encontraban de gira por Chile. Quienes entraron quedaron a prueba durante seis meses, y expresa, románticamente, al respeto: "Había devoción por nuestro trabajo, a pesar de las exigencias" (Giorello, 2005: 121). Del mismo modo, Elena Pérez comenta que cuando ella ingresó, en 1939, con 15 años, formaba parte de un grupo llamado bailarinas extraordinarias con contrato hasta el mes de noviembre y sólo si las necesitaban, las volvían a llamar. Efectivamente, en enero las requirieron ya que era la Fiesta de la Vendimia y el Cuerpo de Baile no podía participar, y así continuaron convocándolas, sin contrato escrito, por varios años. Ingresaron como Supernumerarias - categoría que luego se eliminó-y cobraban \$ $\$ 60$ por mes, participando como suplentes en todos los bailes.

Tanto la categoría de Refuerzo como de Supernumeraria/o y de Subcontratados/as no pertenecían al Cuerpo de Baile. Era un grupo de reserva explotado. No tenían vacaciones ni ninguna carga social. "Se ha llamado de distintas maneras, [explica Moscheni] (...) la historia es la misma, no pertenecían al Ballet Estable pero las usaban, las exprimían como locas, y les prometían que al año siguiente iba a haber concurso" (Moscheni, Pérez y Pinto, 2015). Esto fue así hasta 1947.

Por su parte, una bailarina Solista, es decir, un cargo más alto, en 1954, tenía "un sueldo básico de $\$ 1.475 \mathrm{~m} / \mathrm{n}$, más un sobresueldo de \$120 m/n.; \$200 bonificación por costo de vida, más la bonificación establecida por decreto $\mathrm{N}^{\circ} 28855 / 953$ " (Manso, 2009: 57). Uno de los extras que podía adjuntarse a este sueldo era, por ejemplo, tener un parlamento en una obra. Para lo cual, en 1955, se pagaba \$100 extra por función (Manso, 2009: 60).

Asimismo, a los bailarines varones se les pagaba porreglamento, un porcentual adicional para ensayar y/o actuar junto a una bailarina Solista o Primera Bailarina. "Fueron conquistas de las que todos nos beneficiábamos. Este sobreprecio existe hoy todavía", comenta Moscheni (cit. in Manso, 2009: 49).

De todos modos, los/as bailarines del Colón contaban con ingresos extra a partir de sus participaciones en películas y publicidades. ${ }^{2}$ También participaban de giras por las provincias u otros países, en compañías organizadas por empresarios o Primeros Bailarines. Dichas presentaciones se realizaban los fines de semana que no tenían función o en sus vacaciones. Asimismo, muchos/as ejercían la docencia, en las escuelas de danza estatales, en estudios privados o en escuelas del interior del país.

En cuanto a las condiciones de trabajo, a pesar de que el participar de una institución oficial brindaba mayor seguridad, la inestabilidad política de nuestro país se veía reflejada en las sucesivas cesantías y jubilaciones ${ }^{3}$ de los/as bailarines. Si bien había concursos, la precariedad del/a bailarín/a se veía afectada por intereses extra-artísticos. De todos modos, ocurrieron mejorías respecto a su precariedad laboral, conquistas ganadas por sus reclamos. Estas se ven reflejadas en las remuneraciones enunciadas anteriormente. Otra muestra de ello es que a partir de 1947 todos/as los/ as bailarines pasan a ser estables, recuerda Pinto - quien fue delegado sindical-, eliminándose, por ejemplo, las categorías de "1era y 2da fila" en el Cuerpo de Baile e ingresando por concurso (Moscheni, Pérez y Pinto, 2015).

Asimismo, hay que considerar también problemáticas respecto a las condiciones materiales de trabajo. Como es sabido, los/as bailarines, al igual que los/as actores/ actrices exponen constantemente su cuerpo. Sus cuerpos son su materia prima e instrumento laboral. Por lo tanto, su salud se vuelve central a la hora de hablar de las condiciones laborales. Por ejemplo, la emblemática sala de ensayo la rotonda, era considerada insalubre por el gremio (uno de los motivos de la huelga de 1935). Esta sala está emplazada en el primer subsuelo del Teatro Colón y no contaba
2. Para saber más acerca de la relación entre danza y cultura de masas durante las décadas de 1940 y 1950, y leer análisis sobre la danza en el cine de la época, ver Cadús, 2017b. 3. No contamos con datos que nos permitan exponer acerca del régimen jubilatorio de los/as bailarines del Teatro Colón de la época. Sabemos, a partir de los distintos relatos, que la jubilación anticipada muchas veces fue utilizada como modo de apartar a bailarines de sus cargos, por otro tipo de motivaciones que no era la defensa de sus derechos como trabajadores. Posteriormente, en 1974, se estableció el régimen jubilatorio llamado $20 / 40$, un régimen especial de retiro para que los/as bailarines se jubilaran con 20 años de servicio y a los 40 años de edad, como mínimo, aunque podían optar por continuar en actividad luego de esa edad si querían y se encontraban en condiciones físicas satisfactorias. Pero en el neoliberalismo de los noventa, se lo consideró como una “jubilación de privilegio” y se derogó. Primero, ocurrieron una serie de modificaciones en la relación laboral que significó el cese del cobro por antigüedad, por diferencia de cargo y por presentismo, además del paso de su caja jubilatoria a la Nación (ANSES). Luego, perdieron los registros de los aportes de los empleados-cifras que, por otra parte, eran muy reducidas, dado que acostumbraban cobrar hasta más de la mitad del sueldo "en negro"-. Y, finalmente, en diciembre de 1996, se suspendió la aplicación de la ordenanza municipal 29.604, la del 20/40 (La Nación, 2008). En la actualidad, los/as bailarines están luchando por conseguir nuevamente el 20/40 para todas las compañías estatales (Chertkoff, 2015) (Ver https:// www.facebook.com/leydejubilacionparabailarinesnacionales/). 
con la ventilación adecuada. Además, el desencadenante de la huelga de 1935, fue que, tras diez horas continuadas de trabajo, algunos bailarines caían desvanecidos (Manso, 2009: 28). Por ello, los/as bailarines decidieron exigir la misma normativa que la Orquesta y el Coro estables, quienes tenían dos servicios diarios y el lunes descanso. Pero la respuesta ante el reclamo, por parte de la Dirección del Colón, fue expulsar a los bailarines que se dirigieron a hablar con el Director, a saber, Raúl Dall'Lago y Aurelio Molina y Vedia, quienes no sólo fueron exonerados, sino también detenidos y alojados en un calabozo de la Comisaría $3^{\text {a }}$ (Manso, 2008: 74-5). Por este motivo, se plegaron a la huelga todos los Cuerpos Estables hasta conseguir la liberación de los bailarines. Luego, el asunto pasó al Consejo Deliberante que dio la razón a los bailarines y después de seis meses, Dall'Lago y Molina y Vedia se reintegraron al Colón -con una suspensión de un semestre cada uno-, y se redujo a la mitad las penalidades impuestas a otros/as veinticuatro bailarines/ as que participaron del reclamo (Manso, 2008: 75). No obstante, dichas sanciones costaron al teatro el alejamiento de dos bailarinas: Mercedes Quintana, quien tuvo una vasta carrera como coreógrafa y docente; y Ana María Gambier, quien a partir de ese momento se dedicó al teatro y al cine adoptando el nombre de Niní Gambier (Manso, 2008: 75; 2009: 28).

Para solucionar el problema de la "rotonda", recién en 1948 -trece años después de la huelga- se construyó una sala para el ballet y la Escuela, sobre la calle Cerrito, frente al teatro, entre las actuales Toscanini y Viamonte -donde aún no existía la Avenida 9 de Julio- (Manso, 2009: 45). Sin embargo, a las pocas semanas el Cuerpo de Baile expresó sus reclamos (que la sala "no tenía aire", "que hacía frío", "que el piso resbalaba") -según Moscheni infundados-, y regresaron a ensayar a la rotonda (Manso, 2009: 45).

Por otra parte, a partir del gobierno de Perón, los/as bailarines son sindicalizados como obreros municipales. Cuenta Moscheni al respecto:

(...) en otra oportunidad reuniéndonos, ya teniendo todos el Carnet de la Unión de Obreros Municipales, [Perón] nos aconsejó: - “Yo se [sic] que ustedes están desconformes donde fueron ubicados, les aconsejo que se busquen un gremio que se asemeje a ustedes, de artistas, actores, pero tienen que estar adheridos a un partido porque es muy importante en este momento-". (...) Entonces muy contentos nos fuimos a inscribir a la Asociación Argentina de Actores, y por supuesto nos tomaron a todos, pagando la cuota impuesta. Al poco tiempo tuvimos un problema por un trabajo en Chile y fuimos a buscar defensa en ellos. Pero sus abogados nos dijeron que no entendían nada de ballet y que teníamos que irnos a otra parte. Volvimos entonces a la Unión de Obreros Municipales, donde ya estaban adheridos los médicos y los recolectores de basura, entregándonos finalmente el carnet con letras doradas, muy grandes, titulándonos "Los Misioneros de Perón" (cit. in Manso, 2009: 44).

Al sindicalizarse en la Unión de Obreros Municipales, los/as bailarines de ballet se estarían reconociendo principalmente como trabajadores, y específicamente, como empleados públicos. Si bien la tensión entre artista -en el sentido griego de aquel que se dedica al arte culto sin usufructo económico- ${ }^{4}$ y trabajador-en este caso al mismo nivel que un médico o un recolector de basura- permanece en lo discursivo, los/as bailarines de ballet optan por defender sus derechos laborales, cuestión que el gremio de actores no les aseguraba. Esta es una diferencia notoria con el sector no-oficial de la danza moderna que expondremos en el próximo apartado.

El gremio, entre otras cuestiones, regulaba la legitimidad de los concursos, tal como relata Moscheni en referencia a su concurso de 1954:

4. La condena al usufructo de la actividad artística se origina en la Grecia Clásica, donde tanto en las prácticas artísticas como deportivas el ciudadano debía renunciar a la utilidad que pudiera obtener de las mismas. Esta concepción del artista vocacional, que renuncia -o aparentemente renuncia- al rédito económico por su trabajo sino que su misión refiere al "bien común", transmitiendo un mensaje que eleve o emancipe al público, se halla en la base de la visión dominante en el mundo de la cultura y de las artes en nuestra sociedad (Mauro, 2015: 8). Simultáneamente opera una acusación a quienes no renuncian a ganar el sustento mediante su trabajo. Se genera así la división entre un "nosotros culto" y un "ellos inculto o rapaz" (Mauro, 2015: 8). 
(...) se llamó a concurso a todas las categorías que cada dos años por reglamento se debía realizar, solamente para ascender los de Cuerpo de Baile. Era en el mes de Julio y yo me presenté al rubro de "Solistas y Reemplazantes de Primeros Bailarines". El jurado estaba compuesto por muchas personas, los Maestros Borovski y Tomin, los Delegados del Cuerpo de Baile - que ya empezaban a tener fuerza - y un invitado que por reglamento debía ser extranjero, en ese caso Heinz Rosen, y el Director del Colón, que en caso de empate, a él le tocaba desempatar. A éstos se sumó un Delegado de la CGT, de quien nunca supimos el motivo de su asistencia (cit. in Manso, 2009: 56).

Como mencionamos anteriormente, las condiciones laborales de estabilidad también estaban sumidas a la inestabilidad política. Prueba de ello es lo sucedido tras el golpe de Estado que derrocó a Perón en 1955. En primer lugar, dejaron cesante a la famosa Primera Bailarina y maestra María Ruanova, así como a su esposo, el músico y delegado Cayetano Carbone, ya que eran acusados de peronistas. Y vuelven al Colón: Ada Kristel, Josefina Schiepati y Paula Svagel (Manso, 2009: 66).

Además, en 1957, con el propósito de exigirun mayor grado de eficiencia en los cuerpos estables, se puso en práctica el procedimiento de intervención de la Junta Calificadora (integrada por el Director General, el Artístico y el Administrativo). Luego, de acuerdo a sus dictámenes, se pronunciaría la Junta Asesora de Eficiencia Profesional. El Sindicato Argentino de Músicos y la Asociación del Profesorado Orquestal consideró dicha medida como antirreglamentaria e ilegal, por ello tomaron la medida de paralizar las orquestas Estable y Sinfónica de la Ciudad de Buenos Aires (hoy Orquesta Filarmónica de la Ciudad de Buenos Aires) y la consiguiente supresión de la temporada lírica (Caamaño cit. in Manso, 2009: 67). Cuenta Moscheni:

Una lista de más de quince nombres entre chicas y muchachos llegó a "la rotonda", para presentarse en un día señalado, con un jurado que presidía Ernest Uthoff, director del Ballet de Chile, el Delegado del Cuerpo de Baile que era Luís Casa, y con dos delegados más, obligatorios, de los gremios, alguien por la Escuela de Baile, y la directora del Ballet, Ekatherina de Galantha. Fue por primera vez que sentimos una situación extraña, cumpliendo con el reglamento que nunca lo habían puesto en práctica (cit. in Manso, 2009: 66).

Pero el Ballet no se plegó a la huelga.

(...) nos dejaron solos al Coro y al Ballet a disposición de la Junta de Eficiencia [comenta Moscheni] y todos los señalados quedaron cesantes y a algunas Solistas con kilos demás se les dio 3 meses de plazo para ponerse en forma. Las orquestas, a sus pedidos recibieron adhesiones de importantes instituciones musicales extranjeras. La temporada lírica se suspendió. La huelga se levantó al término del contrato del Sr. D’Urbano [Director Delegado del Colón] (...) (cit. in Manso, 2009: 67).

Como se puede observar, las condiciones laborales de los/as bailarines, a pesar de formar parte de una institución oficial - lo cual brindaba mayor estabilidad en la época-, se veían modificadas no sólo por sus reclamos y disputas, sino también por los cambios gubernamentales.

\section{Bailarines no-oficiales}

El Ballet Winslow marcó el inicio profesional de otro modo de danza, no-oficial, la danza moderna. Formó a bailarines y bailarinas que comenzaron a presentarse en 
diversos teatros, principalmente como solistas pero luego también crearon compañías propias y enseñaron en estudios privados e instituciones estatales. Al respecto, cuenta Renate Schottelius: "Tengo que aclarar que a partir de ser contratada por Miriam Winslow, pude, por suerte, dejar todo mi trabajo de secretaria en distintas oficinas. Cuando se disolvió el conjunto yo seguí solamente en mi tarea profesional de maestra" (Isse Moyano, 2006: 25). También comenta sorprendido, Rodolfo Dantón: "Primero tuvimos todo un año de preparación, de formación, donde cobrábamos para estudiar. Eso era rarísimo" (Isse Moyano, 2006: 58). Sin embargo, para quienes debían aportar dinero a sus familias, el sueldo ofrecido era insuficiente, por ejemplo, Luisa Grinberg, quien tenía seis hermanos - de los cuales cinco eran menores que ella - cuenta que no pudo aceptar el contrato de Winslow ya que este requería exclusividad por cinco años y "no cubría las necesidades económicas" que debía afrontar en su casa (Isse Moyano, 2006: 43).

A pesar de esta experiencia profesional, las demás compañías sólo pagaban las funciones realizadas. Por ejemplo, relata Paulina Ossona que cuando bailó para la compañía de los Sakharoff ellos no pagaban los ensayos: "Pero [dice] les dábamos todos los ensayos que quisieran, de la mañana a la noche, porque nos hacían sentir artistas y teníamos que tener esa responsabilidad, por amor a lo que hacíamos, por amor a la coreografía, por amor a ellos, por amor al arte y a la danza" (Isse Moyano, 2006: 35). Expresando aquí una actitud devocional y sacerdotal en relación a su trabajo como artista de la danza.

Todos/as los/as bailarines que pertenecían al circuito no-oficial, debían dictar clases para subsistir. No obstante, estas pioneras de la danza moderna argentina, tendrían que luchar para ser legitimadas. Al respecto, recuerda Luisa Grinberg, acerca de las clases que dictaba en la década del cuarenta:

Fue una técnica que me costó mucho imponer, porque la gente cuando se le decía danza moderna, pensaba que era tango, o algo así. En mi estudio yo enseñaba danza moderna, pero en principio nadie supo qué era danza moderna. Como no pude poner ese nombre porque moderna era una palabra que estaba mal vista, entonces daba una clase de danza clásica y la otra se llamaba Introducción a la Danza. Después, a los alumnos de mi escuela empezó a gustarles esa clase y cuando eso entró bien, yo ya empecé a llamarlo como correspondía, danza moderna (Isse Moyano, 2006: 45).

Asimismo, otros/as bailarines que no necesariamente dictaban clases, tenían que trabajar en otros estilos de danza para ganar un sueldo fijo. Muchos/as de ellos/as bailaban en boittes, es decir en locales nocturnos a los que la gente salía a tomar algo, bailar y ver espectáculos musicales, de danza y de varieté. Así lo cuentan por ejemplo, Otto Werberg, quien debía ganar dinero para poder traer a su familia que escapaba de los nazis (Isse Moyano, 2006: 51); Estela Maris, quien relata que bailaban en el Embassy que funcionaba en Galería Van Riel (Florida 659) (Isse Moyano, 2006: 66); y Rodolfo Dantón, quien rememora que cuando terminó el servicio militar bailó en una boîte en Lavalle y Florida, junto a otros/as bailarines del Colón (Isse Moyano, 2006: 57).

Si bien estos/as bailarines encontraban la manera de vivir de la danza, debían producir ellos/as mismos/as sus obras. De este modo, consideramos que se inició un modo de producir danza que persiste hasta el día de hoy, en el ámbito de la denominada danza independiente (Ver Pritz y Kovadloff, 2012). Un modo de producción sacerdotal, motivado por la devoción y la entrega, el sacrificio para con la danza. Así lo cuenta por ejemplo Renate Schottelius: "Daba muchísimas clases durante toda la semana. A la vez elaboraba nuevas obras solistas, daba recitales en el Teatro Alvear, en el Teatro Smart, en el Teatro Astral e iba de gira al interior" (Isse Moyano, 2006: 25-26). 
Agregando que, en aquel momento había varias sociedades de conciertos en las ciudades grandes del interior, las cuales contrataban artistas. "Era muy lindo y había mucho movimiento [relata Schottelius]. Había mucho público y se hacía todos los años, casi como un circuito. Pagaban el viaje, la estadía y un cachet. De manera que yo iba con mi pianista y a veces, también, con mi percusionista. No fui la única. María Fux y Paulina Ossona también fueron por estos circuitos" (Isse Moyano, 2006: 26).

Identificamos este modo de producción con aquel modelo de artista, y modelo de vida, del romanticismo. Uno de los elementos básicos del romanticismo es la "autorrepresentación del artista" como un ser aparte, iluminado, en soledad, "sometido al furioso ímpetu de su deseo de alcanzar 'lo bello', de servir al 'arte"' (Myers, 2005: 30), cumpliendo con el sacerdocio que le exige el arte. Tal como expresaba la revista de la época -dirigida a las/os bailarines-, Danza. La revista de la gente que baila, en su nota editorial: "Los bailarines son pobres muchísimas veces, pero sus trajes y sus comidas están bañados en una alegría y una despreocupación que nosotros pagaríamos a muy alto precio" (1954:3).

La dicotomía entre la concepción del artista culto que renuncia al usufructo económico por vocación y devoción al arte, frente a aquel comercial -y por oposición, inculto- que decide ganar dinero con el arte, aparece en el plano discursivo de las/os bailarines de la época. Pero en la práctica, como se deduce de la descripción realizada hasta el momento -actuaban en boîtes y exponían sus espectáculos en teatros independientes, comerciales y oficiales-, todo se volvía más difuso. El ámbito oficial y el no-oficial se mezclaban con el comercial como modo de supervivencia económica frente a la precariedad de su trabajo.

No obstante, notamos una diferencia entre los/as bailarines de ballet - pertenecientes al ámbito oficial-y las/os de danza moderna-del ámbito no-oficial-, a la hora de hablar de sus carreras artísticas como trabajo. Esto se evidencia en las múltiples citas que hemos realizado a lo largo del presente artículo. Los discursos -en entrevistas y en sus biografías- de los/as bailarines de ballet hacen mayor referencia a diferentes aspectos de su condición de trabajadores, mientras que aquellos de la danza moderna, apuntan a la concepción del artista vocacional. Quizás, esta fue una estrategia para legitimar a la danza moderna como culta, como una vertiente más de la práctica de la danza argentina (Cadús, 2017a; 2017b); mientras que el ballet, desde sus inicios, participó de la esfera estatal. El ballet se inicia como práctica artística en 1661, en la corte francesa de Luis XIV, con la fundación de la Academia Real de Música y Danza. Consideramos que esta tradición marcó a la profesión del/a bailarín/a de ballet, quienes si bien se consideraban artistas cultos, también se consideraban trabajadores con derechos en los marcos institucionales y gubernamentales en los que participaban.

Claro que este modo de producción precario de la danza moderna argentina afectaba también a las obras y su carácter estético. Por ejemplo, María Fux realizó su primer espectáculo con ayuda de su reciente esposo: "Ambos eran pobres y los gastos que demanda un espectáculo representaban una barrera poderosa que la audacia y el ingenio juveniles ayudaron a sortear", cuenta en su biografía compilada por Paulina Ossona (2003). "Sobre una sola malla, cortinas hábilmente cosidas por la madre compusieron el vestuario. El salón de actos de la Asociación Científica les fue alquilado por veinte o treinta pesos y en su escenario desplegó María sus primeras creaciones" (100). Asimismo, cuenta Ossona que recién pudo contar con escenografía para una obra de su compañía Nueva Danza, cuando montó un espectáculo en el Teatro Argentino de la Plata (Isse Moyano, 2006: 36), es decir, cuando participó de la programación de una institución oficial. Por ello también, si bien estas bailarinas pioneras de la danza moderna tenían sus compañías, muchas veces optaban por el formato solista, especialmente para las giras. Dice Ossona: "Era más fácil que una institución pagara 
a un solista y no que se pagaran los transportes, la hotelería y todos los gastos de un conjunto. Pero después también hice giras con el grupo. Éramos una cooperativa: yo ponía todos los gastos y después dividíamos las ganancias. Siempre se pierde plata con la danza" (Isse Moyano, 2006: 37).

Como es posible observar, el sistema de producción se parece al actual, que también se autodenomina como cooperativa y que coloca a los/as artistas en un nivel de precariedad laboral extremo, aunque siempre justificado por la devoción al arte. Este lugar romántico del arte y del artista como un sacerdocio, quizás también les impedía reflexionar acerca de su condición como trabajadores. Ya que, en contraste con las instituciones oficiales, estos/as bailarines no se sindicalizaron ni organizaron conjuntamente para trabajar de un modo más justo. Y si bien habían tenido la experiencia de bailar en una compañía profesional, no manejaban las suyas propias del mismo modo. Incluso, por ejemplo, Renate Schottelius tuvo la experiencia de ser invitada a bailar en una compañía estadounidense pero el sindicato local de bailarines no se lo permitió por ser extranjera. Cabe recordar que en Estados Unidos, los/as bailarines de danza moderna estaban organizados desde los años treinta (Franko, 2002). Sin embargo, ni esta experiencia, ni la de los/as bailarines oficiales argentinos fue replicada por la danza moderna del país.

Además, la precariedad en el ámbito de la danza no-oficial, al igual que en la actualidad, también remite a los riesgos laborales que la disciplina implica. A diferencia de los/as bailarines del Colón, que podían hacer una huelga frente a reclamos de condiciones laborales, el sistema de cooperativa de las/os bailarines de la danza moderna impedía esta modalidad de protesta. En base a los relatos con los que contamos, deducimos que la asistencia médica y licencias por lesiones físicas así como sus jubilaciones, dependían de ellas/os mismas/os, hasta que se insertaban a alguna institución oficial -muchas de estas bailarinas, por ejemplo, fueron docentes en profesorados de danza-.

Asimismo, consideramos que esta situación laboral afectó a la producción artística. Por lo tanto, los llamados recitales solistas, tan populares en la época, podrían haber significado no sólo que cada una de estas bailarinas estaba en la búsqueda de su propio lenguaje expresivo, sino que esta imagen romántica de las bailarinas también estaría ligada a la imposibilidad de sostener económicamente una compañía.

\section{Palabras finales y mirada hacia el presente}

A lo largo del presente artículo hemos intentado reconstruir las condiciones laborales de los/as bailarines durante la primera mitad del siglo XX, haciendo particular hincapié en el primer peronismo. Consideramos que es en este momento cuando se alcanza la consolidación de la práctica de la danza escénica argentina y su consecuente profesionalización.

Distinguimos por un lado, al ballet como estilo desarrollado prácticamente en su totalidad en el ámbito oficial, dependiente del Estado. Analizamos en este punto, al Ballet Estable del Teatro Colón y los avances en los derechos laborales de los/as bailarines alcanzados a partir de 1947. Asimismo, destacamos que si bien el pertenecer a una institución oficial generaba mayor estabilidad laboral, la precariedad continuaba en tanto la inestabilidad política estatal del país provocaba avances y retrocesos en los derechos conquistados.

Por el otro lado, la danza moderna, perteneciente al ámbito no-oficial, estableció un modo estético de representación (solos de bajo presupuesto) y un modo de trabajo caracterizado por la precarización laboral de las/os bailarines -denominado desde ese 
entonces como cooperativa-, quienes sólo conseguían mejores condiciones laborales, cuando podían producir para la esfera oficial.

En este sentido, consideramos que en las décadas de 1940 y 1950 en primer lugar, se consolida la práctica de la danza escénica argentina, y en segundo lugar, se establecen dos modos de producción diferenciados que persisten hasta la actualidad, con leves modificaciones.

El trabajar en el ámbito oficial, otorga a los/as bailarines de ballet mayor estabilidad y derechos laborales, mientras que en el caso de la danza contemporánea (que siguió a la danza moderna), se constituye un modo de producción basado en la autoexplotación, enmascarado por el llamado sistema de cooperativa, trabajando por proyectos y rara vez como compañía, y la producción de obras se realiza o bien con fondos propios o con subsidios estatales que cubren únicamente parte de lo material de una obra escénica. Sólo recientemente, el Instituto para el Fomento de la Actividad de la Danza no Oficial del Ministerio de Cultura del Gobierno de la Ciudad de Buenos Aires (Prodanza), estableció que un porcentaje del presupuesto presentado para aplicar al subsidio, debe ser destinado al cachet de los/as intérpretes. Y del mismo modo, lo implementó la Bienal de Arte Joven.

En este modo de trabajo de la danza contemporánea, tal como propone Bojana Kunst (2015), la labor artística se acerca al capitalismo a partir de sus modos de producción (la cercanía entre arte y vida), pero, a su vez, resiste a la apropiación por parte del capitalismo del poder de creación del ser humano. Los/as artistas de la danza contemporánea frecuentemente critican este sistema en el cual se ven imbuidos pero en sus prácticas e instituciones terminan utilizando los mismos modos de explotación. Así, según Kunst, el/la artista deviene un prototipo del trabajador precario y flexible, en constante disponibilidad (disolviéndose así la diferencia entre trabajo y tiempo libre), ya que su trabajo está conectado con la producción de la vida misma (producción de subjetividad y de exceso de sociabilidad) (Ver Cadús, 2015).

Asimismo, tal como hemos planteado en el presente escrito, persiste hasta el día de hoy, una concepción romanticista del trabajo en danza, justificando la explotación laboral y la precarización, con concepciones religiosas románticas de devoción al arte. 


\section{Bibliografía}

" Anteproyecto de Estatuto de Trabajador Intelectual. (1949). Buenos Aires: Ministerio de Educación-Secretaría de Cultura-Junta Nacional de Intelectuales.

"Benjamin, W. (2011). Conceptos de filosofía de la historia. Buenos Aires: Agebe.

"Cadús, E. (2017a). “La consolidación de la práctica de la danza escénica durante el primer peronismo". Revista Digital de Estudios de Crítica Cultural Afuera, noviembre 2016-marzo 2017 (17/18), sin paginación, [en línea]. Consultado el 15 de septiembre de 2017 en https://drive.google.com/file/ d/oBy451f3DM8N3MDN2SIZfZjFOcoE/view

»Cadús, E. (2017b). La danza escénica durante el primer peronismo. Formaciones y práctica de la danza y políticas de estado. Tesis doctoral inédita, Facultad de Filosofía y Letras, Universidad de Buenos Aires.

»Cadús, E. (2015). "Reseña del libro Artist at Work: Proximity of Art and Capitalism”. Telondefondo. Revista de Teoría y Crítica Teatral, año XI, diciembre 2015 (22), 150-152, [en línea]. Consultado el 21 de febrero de 2018 en http://www. telondefondo.org/numeros-anteriores/numero22/articulo/59o/artist-at-workproximity-of-art-and-capitalism.html

»Chertkoff, L. (2015). “Jubilación para bailarines: un tema pendiente”. Revol. Girar las danzas, 28 de julio de 2015, sin paginación [en línea]. Consultado el 26 de febrero de 2018 en http://revistarevol.com/principales/jubilacion-parabailarines-un-tema-pendiente/

»Danza. La revista de la gente que baila. (1954). №1, diciembre. Buenos Aires.

" Franko, M. (2002). The Work of Dance. Labor, Movement, and Identity in the 1930 . Middletown: Wesleyan University Press.

» Giorello, E. (2005). “Esmeralda Agoglia, primera bailarina”, en AA. VV., Memoria y presente del Ballet del Teatro Colón 1925-2005. (pp. 119-129). Buenos Aires: Teatro Colón.

" Guía quincenal de la actividad artística e intelectual argentina. (1949). № 49 . Año III. Segunda quincena. Agosto. Buenos Aires: Comisión Nacional de Cultura.

"Isse Moyano, M. (2006). La Danza Moderna Argentina cuenta su Historia: historias de vida. Buenos Aires: Artes del Sur.

» Kunst, B. (2015). Artist at Work: Proximity of Art and Capitalism. Winchester, UK, y Washington, USA: Zero Books.

»La Nación. (2008). “La jubilación, un problema en danza”. 18 de agosto de 2008.

» Lifschitz, L. (2008). "La Guía Quincenal o de la inserción de la cultura letrada en el primer gobierno peronista". Actas del Primer Congreso de Estudios sobre el Peronismo: La Primera Década. Mar del Plata, [en línea]. Consultado el 17 de abril de 2017 en http://redesperonismo.com.ar/biblioteca/actas-del-1er-congreso/

"Lommi, E. (2015). Entrevista Personal, 21 de mayo (grabada).

»Manso, C. (2009). Beatriz Moscheni. En la Danza. Buenos Aires: De Los Cuatro Vientos.

»Manso, C. (2008). “Cuatro décadas del cuerpo de baile del teatro Colón (1919 a 1959)”, en Durante, B. (Coord.), Historia General de la Danza en la Argentina. (pp. 51-141). Buenos Aires: Fondo Nacional de las Artes. 
» Mauro, K. (2015). “Trabajo asociativo y Actuación: las cooperativas teatrales y la gratuidad crónica del trabajo actoral”. XI Jornadas de Sociología, Facultad de Ciencias Sociales, UBA, Buenos Aires [en línea]. Consultado el 22 de febrero de 2018 en https://www.aacademica.org/o0o-061/534

» Moscheni, B., Pérez E. y Pinto E. (2015). Entrevista Personal, 22 de mayo (grabada).

» Myers, J. (2005). “Los universos culturales del romanticismo. Reflexiones en torno a un objeto oscuro". En Batticuore, G., Gallo K. y Myers J. (Comps.), Resonancias románticas: ensayos sobre historia de la cultura argentina 1820-1890. (pp. 15-46). Buenos Aires: Eudeba.

"Ossona, P. (2003). Destinos de un destino. La danza moderna argentina por sus protagonistas. Buenos Aires: Talaza.

"Pritz, S. N. y Kovadloff, V. (Comps.) (2012). Ejes en danza 2011: encuentro de gestión para el desarrollo de la danza independiente. Buenos Aires: Ministerio de Cultura-Gobierno de la Ciudad Autónoma de Buenos Aires.

" Tambutti, S. (2011). El "nosotros" europeo. Clase universitaria del Seminario Reflexiones sobre la danza escénica en Argentina. Siglo XX. Ficha de cátedra, inédita. UBA, FFyL, Artes. 